\title{
Las emociones en el desarrollo del juicio moral, en perspectiva de educación filosófica*
}

\author{
Nelson Iván Bedoya Gallego** \\ Elías Manaced Rey Vásquez ${ }^{* * *}$ \\ William Harold Romero Neisa****
}

Recibido: 20 de agosto de 2014 - Revisado: 25 de septiembre de 2014 -

Aprobado: 12 de diciembre de 2014

\section{Resumen}

Como resultado de una investigación aplicada, el presente artículo ofrece un análisis crítico sobre el lugar de las emociones en el campo educativo. Basados en la clasificación de Cheshire Calhoum y Robert Solomon (1992), se opta por la propuesta evaluativa y cognitiva en la que se inscribe a la profesora Martha Nussbaum, donde las emociones son consideradas como juicios que, en tanto se basan en creencias y orientan a la acción, cumplen un papel esencial en nuestras decisiones. En ese orden de ideas, el documento analiza la propuesta teórica de la emoción como juicio y su importancia en la comprensión de la formación del juicio moral, además del papel de la educación de las emociones en contraste con el intelectualismo moral y desde una perspectiva de educación filosófica. Finalmente se propone que la imaginación, la argumentación y la deliberación en el marco de lo moral, son las dimensiones humanas que se favorecen y privilegian en una educación de las emociones.

Palabras clave: Educación, emociones, juicio moral, imaginación, argumentación, deliberación

* $\quad$ Artículo de investigación, que constituye un avance del proyecto: Relación y coherencia entre los principios de la Vocación Fundamental de Uniminuto con la emoción-acción de la Comunidad Educativa, desarrollado en el marco de la III Convocatoria para el desarrollo y fortalecimiento de la investigación en Uniminuto.

** Magister en Prosocialidad y Logoterapia de la Universidad Autónoma de Barcelona, es Director del Departamento de Filosofía de la Facultad de Ciencias Humanas y Sociales de la Corporación Universitaria Minuto de Dios. Dirección postal: Dg. 81C 72B - 08, Bogotá, Colombia. Correo electrónico: nbedoya@uniminuto.edu

*** Magister en Docencia de la Universidad Salle, es Docente del Departamento de Filosofía y de la Unidad de ética de Bogotá, Colombia. Correo electrónico: erey@uniminuto.edu

**** Magister en Educación con énfasis en desarrollo humano y valores de la Universidad Externado de Colombia, se desempeña como Coordinador académico del Departamento de Filosofía de la Corporación Universitaria Minuto de Dios. Dirección postal: Dg. 81C 72B - 08. Correo electrónico: wromero@uniminuto.edu 


\title{
Emotions in the development of moral judgment, philosophical perspective of education*
}

\author{
Nelson Iván Bedoya Gallego** \\ Elías Manaced Rey Vásquez ${ }^{* * *}$ \\ William Harold Romero Neisa****
}

As a result of applied research, this paper offers a critical analysis of the place of emotions in the educative field. Based on the Cheshire Calhoum \& Robert Solomon's taxonomy (1992), we opted for the evaluative and cognitive framework from professor Martha Nussbaum, where emotions are considered judgments that, based on beliefs that guide action, play an essential role in our decisions. Following this order, the paper analyzes the theoretical proposal of emotion as judgment, and its importance in understanding the formation of moral judgment, in addition to the role of education of emotions in contrast to the moral intellectualism, from the perspective of philosophical education. Finally, it is proposed that imagination, argumentation and deliberation in the context of morality, are the human dimensions that are favored and privileged in education of the emotions.

Keywords: Education, emotions, moral judgment, imagination, argumentation, deliberation.

Research article, which is an advanced development project: Relationship and coherence between the principles of the fundamental vocation of Uniminuto with emotion-action of the educational community, developed in the framework of the Third Call for the development and strengthening of research Uniminuto.

** Master of Prosociality and speech at the Autonomous University of Barcelona, is Director of the Department of Philosophy at the Faculty of Humanities and Social Sciences of the University Corporation Minuto de Dios. Address: Dg. 81C 72B - 08 Bogotá, Colombia. Email: nbedoya@uniminuto.edu

*** Master in Teaching at the Salle University, is Professor of the Department of Philosophy and Ethics Unit of Bogotá, Colombia. Email: erey@uniminuto.edu

**** Master of Education with an emphasis on human development and values of the External University of Colombia, serves as Academic Coordinator of the Department of Philosophy at the University Corporation Minuto de Dios. Address: Dg. 72B 81C - 08. Email: wromero@uniminuto.edu 


\title{
Les émotions dans le développement du jugement moral, en perspective d'éducation philosophique*
}

\author{
Nelson Iván Bedoya Gallego** \\ Elías Manaced Rey Vásquez ${ }^{* * *}$ \\ William Harold Romero Neisa***
}

\section{Résumé}

Comme résultat d'une recherche appliquée, cet article offre une analyse critique sur la place des émotions dans le domaine éducatif. Basés sur la classification de Cheshire Calhoum et Robert Solomon (1992), on choisit la proposition évaluative et cognitive dans laquelle s'inscrit le professeur Martha Nussbaum, où les émotions sont considérées comme jugements qui, tant qu'elles soient basés sur des croyances et elles orientent l'action, elles ont un rôle essentiel dans les décisions. C'est ainsi que le document analyse la proposition théorique de l'émotion comme jugement et son importance dans la compréhension de la formation du jugement moral, en plus du rôle de l'éducation des émotions en contraste avec l'intellectualisme moral et à partir d'une perspective d'éducation philosophique. Finalement, il est proposé que l'imagination, l'argumentation et la délibération dans le cadre de la morale, sont les dimensions humaines qui sont favorisées et privilégiées dans une éducation des émotions.

Mots Clés: Education, émotions, jugement moral, imagination, argumentation, délibération

* $\quad$ Article de recherche, qui est un projet de développement avancé: Relation et la cohérence entre les principes de la vocation fondamentale de Uniminuto avec émotion l'action de la communauté éducative, développé dans le cadre du troisième appel pour le développement et le renforcement de la recherche Uniminuto.

** Maître de Prosocialité et discours à l'Université Autonome de Barcelone, est le directeur du département de philosophie de la Faculté des sciences humaines et sociales de l'Université Corporation Minuto de Dios. Adresse: Dg. 81C 72B - 08 Bogotá, en Colombie. Email: nbedoya@uniminuto.edu

*** Master en enseignement à l'Université Salle, est professeur au département de Philosophie et éthique de l'unité de Bogotá, Colombie. Email: erey@uniminuto.edu

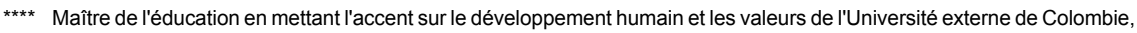
sert de coordinateur académique du Département de philosophie à l'Université Corporation Minuto de Dios. Adresse: Dg.72B 81C - 08. Email: wromero@uniminuto.edu 
La situación de gran parte de la ética del siglo XX se asemeja a un viaje en un barco que, aunque haya tenido que atravesar fuertes tormentas $y$ huracanes, tiene la proa firmemente enfilada hacia su puerto - los derechos humanos - y en el que algunos pasajeros, los filósofos, divagan sobre si hay un viaje moral - cuando ellos mismos están viajando en el barco-, si se puede hablar del viaje-cuando todo el mundo no cesa de hablar de él-o sobre cómo saber hacia dónde ir -cuando todos «saben» a dónde quieren ir $y$ «luchan» por ello - . Estos filósofos-viajeros, al mismo tiempo, excluyen como tema serio de conversación el hablar sobre lo que se siente en el viaje o sobre cómo hacerlo de la mejor manera posible.

La ética siempre tendrá que estudiar si hay un viaje moral de la humanidad y dónde está su estrella polar, pero nunca puede dejar fuera de su consideración cómo viajar, qué se siente o cómo impulsar el movimiento. Esto supone poner el mundo de los sentimientos en el punto de mira de la ética. La filosofía, que tiene un componente de filia, es decir, de sentimiento, no es una mera reflexión fría y abstracta, sino un pensar capaz de reunir bajo su consideración el conocimiento, las acciones, los sentimientos y los valores

Eugenio Fernández

\section{Introducción}

Una de las apuestas fundamentales del proyecto de Filosofía para Niños $(\mathrm{FpN})$, es la formación de la comprensión ética, la cual no solo complementa la dimensión crítica y creativa del pensamiento de orden superior, sino que es esencial y dota de sentido el ideal de la razonabilidad, que subyace a la propuesta educativa de FpN: “La educación entonces ha de verse como el gran laboratorio de la racionalidad, pero es mucho más realista si la vemos como aquel contexto en que los jóvenes aprenden a ser razonables para que puedan crecer como ciudadanos razonables, compañeros razonables y padres razonables" (Lipman, 1991, p. 58).

La comprensión ética será asimilada más adelante como otra dimensión del pensamiento de orden superior, llamado cuidadoso, que no aparece de manera explícita en las primeras definiciones de Lipman, aunque desde el principio, éste haya destacado la importancia de la formación en los niños y jóvenes del juicio moral, la sensibilidad al contexto y el cuidado, que solo es posible desarrollar en un tipo de educación que tenga en cuenta los contextos y experiencias de los estudiantes; que promueva la discusión en torno a aquellos asuntos que les preocupan; que no se centre exclusivamente en el conocimiento, sino que abra espacios o adelante actividades donde se pueda apreciar, valorar, conocer al otro, compartir los sueños y las adversidades, expresar lo que se siente, ponerse en el lugar de los otros, imaginar alternativas, entre muchos otros aspectos de la vida de los estudiantes. 
Desarrollar el pensamiento cuidadoso o la comprensión ética, supone apelar permanentemente a las dimensiones personal y social, aspecto que involucra de manera explícita a las emociones como aquellas que permiten una comprensión más profunda de nuestra humanidad compartida, asunto esencial en una propuesta educativa que entienda que su fin último es el mejoramiento de las condiciones humanas y sociales de las personas.

En esa perspectiva, lo que aquí se expone es el resultado de un ejercicio de investigación en torno a la relación entre emoción, acción y ética, que parte de la hipótesis que la educación de las emociones es una propuesta de formación ética, toda vez que como afirman muchos estudiosos contemporáneos, negar el papel de los afectos, las pasiones o las emociones en las decisiones morales es prácticamente imposible y, en consecuencia, no es posible pensar una propuesta de educación filosófica que no tenga en cuenta a las emociones.

\title{
2. Sobre el estudio de las emociones
}

"Casi todo el mundo piensa que sabe qué es una emoción hasta que intenta definirla. En ese momento prácticamente nadie afirma poder entenderla"

\author{
Wenger, Jones y Jones
}

El campo de estudio de las emociones y los sentimientos ${ }^{1}$ es bastante amplio y complejo, en la actualidad es abordado por diferentes disciplinas, entre las que se destacan la antropología, la biología, la psicología, la sociología, la neurociencia, los estudios culturales y la filosofía, entre otras, que si bien han hecho importantes aportes para su comprensión, coinciden en reconocer que siempre habrán asuntos por explorar al respecto. Asimismo, pese a su actualidad, el estudio de las emociones no es de reciente preocupación, considerarlo así, da cuenta de una perspectiva propia de la modernidad que condenó a las emociones al terreno del control y, por tanto, a la necesidad de "disciplinarlas"2 dada su aparente distanciamiento con la racionalidad, que no favorecía el ideal de la objetividad y el gobierno de la razón, idea que aún persiste en una parte del contexto académico actual. Al respecto, Damasio (2007), uno de los neurocientíficos actuales de mayor relevancia en el estudio de las emociones y los sentimientos, analiza lo que es para él, el mayor error de la modernidad:

1 El término "sentimiento" es utilizado por varios autores como un sinónimo de "emoción", a manera de ejemplo, así lo hacen Adam Smith y David Hume, sin embargo, aunque los estudiosos no se han podido poner de acuerdo, es claro que hay una distinción entre estos dos términos. En este caso lo estamos entendiendo de la siguiente manera: el sentimiento se puede entender como el aspecto fisiológico de la emoción, es decir, su manifestación corporal, mientras que la emoción incluirá puntualmente su aspecto cognitivo. Al respecto Robert Solomon (2007) afirma: "los sentimientos son, por su propia naturaleza, estúpidos y carentes de inteligencia, con independencia de lo que nuestra inteligencia pueda hacer después con ellos [...] Debemos preguntarnos, asimismo, si toda emoción incluye necesariamente sentimientos, pues existen "pasiones tranquilas" (Hume) y emociones estéticas (James) que pueden no exhibir sentimientos evidentes (pp. 193-194)

2 Al respecto, es importante observar las reflexiones que plantea Foucault (1975) al denominar a la escuela junto con las fábricas, los hospitales y las cárceles, como instituciones creadas por la sociedad moderna para controlar, vigilar y castigar, característico de las relaciones de poder propios de dicha sociedad. En ellas y volviendo a la reflexión inicial de este escrito, se busca "racionalizar", disciplinar a aquellos que por su condición o comportamiento son excluidos de la sociedad, dado que alteran el orden, característico de la misma. 
Éste es el error de Descartes: la separación abismal entre el cuerpo y la mente, entre el material del que está hecho el cuerpo, medible, dimensionado, operado mecánicamente, infinitamente divisible, por un lado, y la esencia de la mente, que no se puede medir, no tiene dimensiones, es asimétrica, no divisible; la sugerencia de que el razonamiento, y el juicio moral, y el sufrimiento que proviene del dolor físico o de la conmoción emocional pueden existir separados del cuerpo. Más específicamente: que las operaciones más refinadas de la mente están separadas de la estructura y funcionamiento de un organismo biológico (p. 286, resaltado nuestro).

En esa línea, y haciendo eco al epígrafe que aparece al inicio de este apartado, aunque todos tengamos una idea o por lo menos una intuición sobre lo que son las emociones y reconozcamos, independientemente del sitio que le demos, que forman parte de nuestra vida, definirlas no es un asunto fácil, de hecho existen tantas definiciones como perspectivas de abordaje. Una clasificación que consideramos bastante completa es la adelantada por Cheshire Calhoum y Robert Solomon (1992) expuesta en su libro: ¿Qué es una emoción?, donde presentan cinco teorías: de la sensación (D. Hume) y de la reacción fisiológica (Descartes - W. James), que se centran en las explicaciones causales de las emociones, haciendo hincapié en el "sentimiento real de la emoción"; las conductuales (Darwin - Dewey - Ryle) que como su nombre lo indica, prestan especial atención a las conductas distintivas relacionadas con diferentes emociones; las evaluativas (Brentano, Scheler, Sartre y Solomon) donde lo importante es el "objeto de la emoción" y los "consecuentes juicios de valor positivos y negativos"; y finalmente las de la actividad cognitiva (Peters, Sousa, Solomon, Nussbaum) que se enfocan en el estudio de la "conexión entre nuestras emociones y nuestras creencias sobre el mundo, nosotros mismos y los demás" (p. 14).

Ahora bien, en la perspectiva que hemos venido trabajando, las teorías que consideramos más cercanas al planteamiento propuesto en esta investigación son las evaluativas y cognitivas. En ellas las emociones son consideradas como juicios, que se basan en creencias y orientan a la acción, por lo que cumplen un papel esencial en nuestras decisiones. Esta perspectiva es ampliamente desarrollada por la profesora Martha Nussbaum, la cual pasamos a detallar a continuación.

\section{La propuesta teórica de la emoción como juicio y su importancia en la comprensión de la formación del juicio moral}

Nussbaum (2008) al definir las emociones como formas de pensamiento o juicios evaluativos que forman parte de la vida buena ${ }^{3}$, ofrece un equilibrio al debate 
clásico señalado anteriormente -la supremacía de la razón sobre las emociones-, al considerar que éstas no deben ser eliminadas, controladas o dejadas al margen, en tanto ellas son un aspecto esencial, constitutivo, de la vida misma:

(...) Si una teoría cognitiva-evaluadora de las emociones es correcta, estos postulados adquieren una importancia particular, pues significan que, si se omiten las emociones, se descuidará no un mero apéndice psicológico al pensamiento ético, sino una parte del propio pensamiento ético. Las emociones no son sólo el combustible que impulsa el mecanismo psicológico de una criatura racional, son parte, una parte considerablemente compleja y confusa, del propio raciocinio de esa criatura" (p. 23).

Así, las emociones son constituidas por juicios que nos hacen tomar conciencia de nuestra propia humanidad, de las diversas maneras en que somos vulnerables, de nuestra relación con los demás, con lo que consideramos fundamental y relevante para un buen vivir y con aquello que no está dentro de nuestro alcance, lo que demuestra la importancia de otorgar a las emociones un puesto relevante en el campo de la moral:

En lugar de concebir la moralidad como un sistema de principios que el intelecto imparcial ha de captar y las emociones como motivaciones que apoyan o bien socavan nuestra elección de actuar según esos principios, tendremos que considerar las emociones como parte esencial del sistema de razonamiento ético. No podemos obviarlas razonablemente una vez que reconocemos que las emociones contienen juicios que pueden ser verdaderos o falsos y pautas buenas o malas para las elecciones éticas. Tendremos que enfrentarnos al confuso material de la aflicción, la ira y el temor, $\mathrm{y}$ al papel que estas experiencias tumultuosas desempeñan en el pensamiento acerca de lo bueno y lo justo (pp. 21-22).

En consecuencia, contrario a algunas perspectivas, las emociones no son fuerzas oscuras que distraen a la razón, sino juicios que favorecen precisamente el ejercicio de la misma, en tanto la razón por sí sola (en el caso que pudiésemos hablar de una razón fría sin concurso de las emociones) no es suficiente para dar cuenta de las elecciones humanas para la vida buena. De esta manera, según Nussbaum (2008), hay cuatro aspectos que caracterizan a las emociones como juicios:

1. Que son "acerca de algo", esto quiere decir, que tienen objeto. Sea cual sea la emoción, es tal en cuanto tiene un referente, un algo que la propicia, sin eso sería tan solo una reacción orgánica involuntaria. Ej. La ira puede ser consecuencia de la acción de una persona o un grupo que generó en quien siente la emoción, la idea que está siendo atacado o afectado, y por ende debe reaccionar.

2. Que el "objeto es de carácter intencional", esto es, la emoción corresponde a la percepción e interpretación de quien la experimenta, la forma particular 
de ver la emoción, “Este 'ser acerca de algo' resulta de mis formas activas de percibir e interpretar: no es como recibir una instantánea del objeto, sino que requiere observar el mismo, por así decirlo, a través de nuestra propia ventana" (p. 49).

3. Que encarnan no solo maneras de percibir el mundo, sino "creencias a menudo muy complejas acerca del objeto" (p.51). Ej. En la repugnancia subyace la creencia que aquello que se rechaza puede causar un daño importante a uno mismo o a alguien cercano.

4. Que poseen un valor o importancia para quien las vive, lo que implica que "las emociones tienen un carácter local: adoptan un lugar peculiar dentro de la vida de cada persona y, precisamente ahí, se centran en la transición entre la luz y la oscuridad, al margen de la distribución general de la luz y la oscuridad en el universo en su totalidad. Incluso cuando se interesan por acontecimientos que tienen lugar a distancia o eventos del pasado, es porque la persona ha conseguido investir tales sucesos de cierta importancia dentro de su propio esquema de fines y objetivos" (pp. 52-54).

En suma, las emociones son experiencias vitales que poseen las características de "ser acerca de algo", con intencionalidad, apoyo en creencias y vinculación con la evaluación. Esto quiere decir, que las emociones experimentan y perciben el mundo desde el sujeto, "trasladando los acontecimientos a la noción de éste de lo que posee valor o importancia de carácter personal" (p. 55). De acuerdo con esto, las emociones son parte constitutiva, esencial del pensamiento, a partir de lo cual se puede establecer una profunda relación entre educar emociones $\mathrm{y}$ formar en ética.

\section{Educación de las emociones, más allá de un intelectualismo moral}

Lipman, en "Filosofía en el aula" (1992), plantea la necesidad de que el profesor de filosofía "anime a los alumnos a ver la importancia que tiene llegar a juicios morales bien fundados, que exige en ellos el desarrollo de una sensibilidad, de un interés y de un cuidado éticos", advirtiendo que la propuesta ética de FpN "no está interesada en inculcar reglas o principios morales, sino en familiarizar al estudiante con la práctica de la investigación moral" (p. 145).

En este sentido, y partiendo de la perspectiva de las emociones expuesta anteriormente, pasamos a considerar lo que supondría su educación en el contexto de la FpN, para ello proponemos partir de una pregunta clásica en el contexto de la reflexión ética: “¿En qué medida el reconocimiento de que algo es bueno nos determina a obrar en consecuencia?" cuestión que nos remite a Sócrates, a quien se le adjudica llevar al extremo la importancia de la razón en la ética, incurriendo en el llamado "intelectualismo moral". Lo anterior, dado que el ejercicio investigativo 
desarrollado nos permite afirmar que en la mayoría de las instituciones educativas aún persiste la idea que formar en ética implica exclusivamente educar en normas o reglas que orienten la acción.

El intelectualismo moral supone que sólo con conocer el bien de la norma moral y política, se actúa en consecuencia, y solo aquel que yerra o comete el mal, lo hace por ignorancia, por el desconocimiento de ese bien. En esta línea, se hace pertinente recordar el fragmento tres del poema de Parménides 4 : "lo mismo es pensar y ser", quien comprende el pensamiento humano (razón, capacidad de deliberación) equivalente con el ser o esencia del hombre. En otras palabras, el pensar es el principio de determinación del ser, y por tanto, es el que capta la verdad -deliberando- lo que nos lleva al ejercicio práctico consecuente con dicho conocimiento. Según lo anterior, podríamos afirmar que de alguna manera basta con dar conocer lo que está bien y favorecer ejercicios de deliberación en las aulas para formar el juicio moral, como si se tratara de una técnica para dotar a la razón de criterios morales, que garanticen una acción consecuente. No obstante, en la vida práctica y cotidiana encontramos situaciones que cuestionan la contundencia de la razón o del conocimiento respecto a dicha acción consecuente.

Surge entonces otro interrogante: ¿Por qué conociendo lo que es bueno no actuamos en consecuencia? que abre posibilidades a nuevas y diferentes interpretaciones -como la que aquí presentamos- y que desde la antigüedad ha suscitado el interés de distintos pensadores, entre ellos Aristóteles, quien explicó dicha contradicción, a partir del concepto de debilidad moral (conclusión racional sin sentido pleno, que no ha tenido en cuenta el deseo y las pasiones). Es decir, el obrar bien requiere no solo del conocimiento de la norma o de los criterios morales, sino también del concurso de las emociones, tal y como lo propusieron en su momento Spinoza, David Hume, Adam Smith ${ }^{5}$ y actualmente Nussbaum.

Volviendo entonces a la pregunta inicial, ¿si basta con conocer el bien para obrar en consecuencia?, contrario a los postulados del intelectualismo moral, afirmamos que en la deliberación no sólo actúa la razón, sino que las emociones tienen un papel preponderante en la misma, como movilizadoras de la acción. De ahí que, mientras que para Sócrates solo bastaba con conocer lo que es bueno para actuar bien, para Aristóteles, el conocimiento de lo bueno no es suficiente para obrar bien, es decir, necesariamente no se obra mal por ignorancia; ya que la acción implica la voluntad, el querer hacer ese bien, que es el resultado del pathos o las pasiones.

4 Parménides en DK 28 B3 (Diels H. - Kranz W.).

5 Estos filósofos del siglo XVII y XVIII europeo, vieron en pasiones el centro de la moral, incluso puede afirmarse, que encontraron en ellos el fundamento. 


\section{Educación de las emociones en perspectiva de una educación fillosófica}

La educación de las emociones, desde la concepción de un proyecto de educación filosófica ${ }^{6}$, implica la superación de la idea de control de las mismas y, en línea con lo que se ha venido exponiendo, aboga por dar a estas la importancia que tienen en la formación de una persona razonable. Precisamente, Ann Sharp, quien junto con Lipman sentó las bases e hizo significativos aportes a la conformación del programa de Filosofía para Niños, hace algunos años escribió un artículo sobre la educación de las emociones en la comunidad de diálogo ${ }^{7}$, y aunque el mismo se constituyó en un importante aporte para la comprensión de la noción de pensamiento cuidadoso, llama la atención que si bien la autora hace una crítica a la idea de comprender dicha educación como un control de las mismas, en algunos apartados persiste la idea de una supuesta superioridad de la razón sobre la emoción, como si ambos fuesen opuestos:

“la emoción es la otra cara de la razón; por ello, la educación en conjunto de las emociones y el pensamiento es esencial cuando se pretende lograr un mundo más razonable y bello" (p. 61, subrayado nuestro).

"Si bien es cierto que las emociones pueden conducirnos al extravío, la historia de las ideas sugiere, sin embargo, que con frecuencia una idea del pensamiento, que pone todo el énfasis sobre lo cognitivo, y que carece de conciencia relacional y de inteligencia emocional, ha tenido terribles consecuencias"(p. 64, subrayado nuestro).

Esta última afirmación, que es parte de la conclusión de su artículo, donde ubica lo emocional en un lugar distinto de lo cognitivo, es un asunto contradictorio con la tesis que ella misma plantea sobre las emociones como "juicios que guían nuestras percepciones y todo lo que resulta de importancia en nuestra vida cotidiana" (p. 55) y que compartimos plenamente. Ahora bien, aunque no es nuestra intención hacer una crítica a la propuesta de la autora, o desvirtuar otras perspectivas distintas a las aquí presentadas, identificar éste y otros elementos aquí expuestos, ayudan a ubicar de manera más precisa la idea de educación de las emociones que intentamos presentar, mostrando el valor agregado de la misma en el contexto de un proyecto de educación filosófica.

En primer lugar, queremos destacar que desde esta perspectiva es prácticamente imposible concebir una educación que no apele a las emociones y que, aunque

6 Se propone el concepto educación filosófica, distinguiéndolo del de programa de $\mathrm{FpN}$, atendiendo a la perspectiva propuesta por el profesor Diego Pineda, que plantea que $\mathrm{FpN}$ no puede reducirse a la aplicación del programa de Lipman, sino que supone un proyecto con múltiples posibilidades en el terreno de la educación. Cf. Pineda (2004).

7 Sharp, Ann (2008). Educación de las emociones en la comunidad de indagación. En: Gómez, C., \& Rojas, V. Filosofía para Niños. Ideas fundamentales y perspectivas sociales. Bogotá: Uniminuto. 
algunos sistemas educativos las hayan desconocido o desconozcan con o sin intención, negarlas es negar la humanidad misma, que es hacia donde se dirige toda educación. Aunque valga la aclaración, no estamos afirmando que las emociones son exclusivas de las personas. En segundo lugar, es difícil comprender la razón de ser de las prácticas educativas si no se tienen en cuenta las emociones, los elementos centrales de todos los modelos educativos contienen preguntas por la persona, no solo por el conocimiento y su mediación. En tercer lugar, uno de los objetivos centrales de la educación es la socialización y el encuentro, en donde transitan o afloran naturalmente las emociones.

Particularmente en una educación filosófica, formar personas razonables, significa apelar al cuidado, al reconocimiento de sí mismo y del otro, a la sensibilidad al contexto, a la comprensión ética, a la búsqueda de sentido, a poner en cuestión las normas, reglas y acuerdos sobre las que se sustentan nuestras organizaciones en una sociedad democrática y todo ello supone el concurso de las emociones.

En esa misma línea, Dewey ${ }^{8}$ advierte que si la educación moral no se basa en la práctica y la experiencia no es una educación transformadora, es decir, mientras ésta no se articule con la vida social y con las exigencias actuales, los estudiantes estarán lejos de comprender mejor sus vidas, el mundo y las relaciones con los demás:

La educación moral en la escuela es prácticamente desesperada cuando se afirma el desarrollo del carácter como un fin supremo, y al mismo tiempo se trata de facilitar el conocimiento y el desarrollo de la inteligencia, que necesariamente ocupan la mayor parte del tiempo escolar, como cosas que no tienen nada que ver con el carácter. Sobre tal base, la educación moral queda inevitablemente reducida a una especie de instrucción catequística o lecciones sobre la moral. Las lecciones "sobre moral" significan, de hecho, lecciones sobre lo que otros piensan acerca de las virtudes y los deberes (Dewey, 2004, p. 295).

Precisamente, en Lisa, novela del programa de FpN, escrita especialmente para jóvenes de 14 a 18 años, es donde en mayor detalle se trata el tema de la ética y los problemas morales, desde una perspectiva consecuente con lo que hemos venido exponiendo. En varios apartados Lisa y sus amigos ponen en cuestión conceptos como la justicia, la honradez y la bondad; se preguntan por problemas éticos como ¿por qué comer animales? o ¿por qué apelar a la violencia para resolver un conflicto?; se enfrentan a situaciones trascendentales como la separación y la muerte y en ese trasegar se evidencian distintas emociones, que algunas veces permiten reconocer el alcance ético de algunas decisiones. Es el caso por ejemplo, de una ofensa que hace Lisa a Beto, donde salen a flote

8 La clave de la pedagogía de Dewey consistía en proporcionar a los niños "experiencias de primera mano" sobre situaciones problemáticas, en gran medida a partir de experiencias propias, ya que en su opinión "la mente no está realmente liberada mientras no se creen las condiciones que hagan necesario que el niño participe activamente en el análisis personal de sus propios problemas y participe en los métodos para resolverlos (al precio de múltiples ensayos y errores)" (Dewey, 2004, p. 237). 
emociones como la indignación, la cólera y la culpa, que ayudan a reconocer al grupo y en especial a Lisa que en esa situación no se obró del todo bien:

Lisa: - $\mathrm{iAh}$, no me vengas con cuentos, tu madre se gana la vida limpiando!

Beto se fue. Pero Miguel estaba furioso.

- ¿Por qué le dijiste una cosa así?

Lisa lo miró con extrañeza.

-¿Qué cosa?

- ¡Lo sabes muy bien! Eso de que la madre se gana la vida limpiando.

-No hay nada de malo en eso -dijo Flo- Montones de personas que conozco lo hacen. Es una cosa perfectamente honesta. ¿Estás en contra de la gente que trabaja mucho, a lo mejor?

Pero Lisa estaba estupefacta.

-¡No sabía que era verdad!- se lamentó.

-Ah, vamos, Lisa -dijo Flo como un consuelo-, no creo que a Beto le importara, realmente.

-¡Apuesto que sí! -insistió Miguel-. ¿Cómo te sentirías si alguien hablara así de lo que hacen tus padres?

Flo se alzó de hombros.

-Dejaría que lo hicieran. Estarían gastando saliva.

Pero Miguel no quería dejar las cosas así.

- ¿Ya no es bastante con que al padre de Beto lo mataran en la guerra? Es cierto, su madre tiene una pensión, pero no es mucho. Trabaja haciendo la limpieza en un hotel, y para poder llegar a fin de mes lava la ropa de algunos de los huéspedes. ¡Vamos, no era para que te burlaras de ella, Lisa!

Lisa se quedó sin habla. Nada de lo que Flo dijera podía consolarla.

-Si lo hubiera sabido -se dijo una y otra vez-, lo habría tomado en cuenta y no habría dicho lo que dije. No importa que él no se haya sentido herido. No debería haberlo dicho. -No obstante, en medio de su pesar, se le cruzó por la cabeza una idea un tanto ocurrente: ¡que la próxima vez no hablaría hasta estar segura de lo que quería decir era totalmente falso!

Pero no pudo desprenderse de la sensación de haber hecho algo vergonzoso, aunque no había tenido la intención de dañar a Beto. 
Entonces empezó a preguntarse si realmente no había querido lastimarlo.

- ¿Pero por qué iba a querer hacer una cosa así? Siempre fue agradable conmigo. Y seguro que ya tiene suficientes problemas; no necesita que yo le agregue uno más. $-Y$ entonces se le ocurrió que ésas podrían haber sido exactamente las razones por las que había tratado de herirlo. La idea le dio escalofríos (Lipman, 2007, pp. 17-18).

Finalmente, queremos resaltar que la educación de las emociones supone el concurso de varios factores, que no están supeditados exclusivamente a la escuela, es evidente que la familia cumple un papel fundamental, de hecho toda la sociedad en su conjunto, pues como afirma Nussbaum (2006) “debido a que las emociones involucran una valoración, éstas reflejarán las normas de la sociedad" (p. 63). Sin embargo, ponerlas en el centro de la discusión en el aula se constituye en un factor fundamental para el desarrollo del juicio moral, y en general para la formación de la dimensión cuidante del pensamiento. En esa línea, a partir del rastreo investigativo que hemos hecho, destacamos tres aspectos que pueden ayudar al logro de este ideal:

Favorecer el desarrollo de la imaginación moral, poniendo en discusión en el aula situaciones de la vida real o relatos cercanos a los estudiantes, en donde estos encuentren personajes afectados por situaciones propias de la cotidianidad, emociones como la compasión o la repugnancia, según los estudiosos del tema, se aprenden. La compasión supone el pensamiento de que otra persona o ser vivo está sufriendo sin ser directamente responsable de ello, y que nosotros mismos podemos ser igualmente vulnerables ante las situaciones que generan dicho sufrimiento. En ese sentido, dialogar en torno a una situación que genera compasión va formando en la persona la capacidad de aprender a identificarse con los demás y a sentir, mediante la imaginación, el sufrimiento de ese otro, como lo señala Nussbaum (2011). Por ejemplo, en Lisa encontramos una escena donde se narra su sufrimiento debido a la reciente muerte de su padre:

Permanecieron así durante un rato, Lisa aturdida y silenciosa, Suki amable y paciente. Finalmente, Suki habló.

-Cuando murió mi mamá, lo que sentí debe de haber sido parecido a lo que tú sientes ahora.

Era difícil asegurar que Lisa hubiera escuchado; simplemente siguió mirando el suelo.

Luego de un rato, Suki notó que Lisa se inclinaba hacia delante, luego hacia atrás, luego hacia delante nuevamente. Empezaba a balancearse y siguió haciéndolo bastante tiempo. Después, se detuvo de repente y miró fijamente a Suki. Intentó hablar, pero no lo consiguió del todo. 
Suki extendió la mano y tocó suavemente su brazo. Lisa interrumpió sus intentos de hablar y se derrumbó en los brazos de su amiga, que la acunó y comenzó a mecerla. Todo su cuerpo se sacudía con los sollozos y Suki siguió meciéndola constantemente, mientras le frotaba dulcemente la cabeza y la acariciaba hasta que Lisa se calmó.

Finalmente, Lisa se sentó derecha.

-Estoy bien -anunció. Su voz sonaba ronca y un poco extraña.

-Claro que sí -respondió Suki cariñosamente.

-¡No es justo! -dijo Lisa-. ¡No se merecía morir!

-Todo lo que vive muere en uno u otro momento - dijo Suki con suavidad-. Es natural.

-¡Pero no tenía que morirse justo ahora!-Gritó Lisa- ¡Todavía tenía mucho por vivir! Además, lo natural es terminar lo que empiezas. No simplemente interrumpirlo en el medio. ¡Hasta los árboles envejecen! ¿Por qué él no?

-No sé -murmuró Suki-. Es extraño, sin embargo. Cuando murió mi mamá, no dejé de pensar en cuánto había perdido mi padre. ¡Y ahora tú hablas de cuánto perdió tu madre! ¡Pero las dos cosas son tan diferentes!

-Bueno -replicó Lisa con una voz apagada y sin matices-, ¿qué importa? (Lipman, 2007, p. 96).

Desde aquí, pueden tratarse cuestiones como el valor o el sentido de la vida, la capacidad de ponerse en el lugar del otro, la vulnerabilidad propia de la humanidad, entre otros aspectos, que sin duda al ser discutidos en el aula pueden favorecer la constitución de una actitud empática y el reconocimiento del valor del otro, asuntos centrales de cualquier ética. Personas compasivas tendrán mayores posibilidades de sentir un genuino interés por los demás, ya sean cercanos o lejanos, y difícilmente caerán en actitudes excluyentes. En esa misma línea, una educación filosófica debe poner en discusión en el aula situaciones reales, como por ejemplo: las condiciones de grupos con capacidades diferentes; la exclusión por género, raza o religión, entre otros, como una forma de contrarrestar el rechazo a aquello que se repugna.

Favorecer la capacidad de argumentación moral, ello en sintonía con la compresión de la emoción como una forma de pensamiento. Es decir, en el aula conviene abrir espacios para que los estudiantes puedan dar razones suficientes de lo que están sintiendo, de los motivos que generan ese sentimiento, de las implicaciones de sus posibles decisiones en su propia vida y en la de los demás, como una forma de educar el juicio moral, entendido más allá de un reduccionismo racionalista. Formar en la capacidad de argumentación moral a los niños y jóvenes tiene implicaciones muy importantes, pues les permite 
entender y sustentar el por qué, para qué, cómo y cuándo de la emoción ante un acontecimiento determinado. Por ejemplo, la indignación, es un indicador de que algo que está sucediendo o le sucede a alguien cercano, es injusto e inmerecido. Al comprender las razones de dicha emoción y poder expresarlas de manera clara, se está favoreciendo la actitud ética, así como el aprendizaje de cuando es consecuente, ante diferentes situaciones y contextos, expresar indignación. En otras palabras, ésta emoción potencia la capacidad de disentir y tener el valor de expresar aquello que no se considera consecuente con lo que es justo y equitativo.

Favorecer la capacidad de deliberación moral. Es decir, en el aula conviene poner en discusión situaciones problemáticas que promuevan la configuración de las decisiones prudentes, que emanan de una deliberación juiciosa y dedicada. Al respecto afirma Victoria Camps (2011):

La persona que posee tal elenco de virtudes es porque es, a su vez, prudente, a saber, capaz de aplicar la justa medida a sus emociones o pasiones para no verse dominada por ellas. Ahora bien, la medida objetiva no existe, ya que cada uno encuentra su propia medida de valentía, de templanza, de magnanimidad, de amabilidad o de generosidad. Esa subjetividad del carácter moral pone de relieve que el tal carácter no puede ser un producto de la razón pura (como querrá que lo sea siglos después Kant), sino una manifestación de la manera de ser de cada persona (p.51)

Ser capaz de distinguir, por ejemplo, cuando la repugnancia hacia una situación, un grupo o una persona se justifica o no y que en reiteradas ocasiones esta emoción ha validado la dominación, la discriminación o el rechazo por ciertos grupos raciales o por personas que ostentan ideales contrarios a los nuestros, generando incluso en agresiones y violencia, permite en los estudiantes tener una mayor capacidad de deliberación en el momento que sientan esta emoción $\mathrm{y}$ a valorar el posible alcance de sus acciones.

En síntesis, la educación de las emociones es una búsqueda permanente, un ideal que supone un trabajo dedicado por desarrollar capacidades imaginativas, argumentativas y de deliberación sobre problemas prácticos, es decir, posibilitar un diálogo constante con aquello que nos interesa y nos afecta.

\section{Referencias}

Aristóteles (2011). Ética nicomaquea. Madrid: Gredos, Biblioteca de Grandes Pensadores, T. II.

Camps, V. (2011). El gobierno de las emociones. Barcelona: Herder.

Calhoun, C., \& Solomon, R. (1992). ¿Qué es una emoción? México: FCE. 
Damasio, A. (2007). El error de Descartes. Barcelona: Crítica.

Dewey, J (2004). Democracia y Educación. Madrid: Morata.

Diels, H., \& Kranz, W. (1934). Parménides, en DK 28 B3 (Fragmente der Vorsokratiken / Los fragmentos de los presocráticos). Citado por Di Mauro, E. (1991). El dios genético (p. 151). Madrid: Ediciones de la Torre.

Espinosa A., F. (2007). La razón afectiva en Spinoza. En E. Fernández., \& M. De la Cámara. El gobierno de los afectos en Baruj Spinoza (pp. 57-66). Madrid: Trotta.

Foucault, M. (1999, 1975). Vigilar y castigar. México: Siglo XXI.

Lipman, M., \& Sharp, A. (2002). Filosofía en el aula. Madrid: Ediciones de la Torre. Lipman, M. (2007). Lisa. Buenos Aires: Manantial.

Lipman, M. (1991). Pensamiento complejo y educación. Madrid: Ediciones de la Torre.

Nussbaum, M. (2012). Crear capacidades. Propuesta para el desarrollo humano. Barcelona: Paidós.

Nussbaum, M. (2010). Sin fines de lucro. Por qué la democracia necesita de las humanidades. Barcelona: Paidós.

Nussbaum, M. (2008). Paisajes del pensamiento. La Inteligencia de las emociones. Barcelona: Paidós.

Nussbaum, M. (2006). El ocultamiento de lo humano. Repugnancia, vergüenza y ley. Buenos Aires: Kats.

Pineda, Diego A. (2004). Filosofia para niños: el ABC. Bogotá: Beta.

Sharp, Ann (2008). Educación de las emociones en la comunidad de indagación. En: Gómez, C., \& Rojas, V. Filosofía para Niños. Ideas fundamentales y perspectivas sociales. Bogotá: Uniminuto.

Solomon, R (2007). Ética Emocional, una teoría de los sentimientos. Barcelona: Paidós.

Wenger, M.A., Jones, F.N., \& Jones, M.H. (1962). Emotional behavior. In D.K. Candland (Ed.). Emotion: bodily change. Princeton, N.J.: van Nostrand. 